\title{
ARTIGO - EDUCACÃA POPULAR EM DIREITOS HUMANOS NO PROCESSO DE ALFABETIZACÃO DE JOVENS, ADULTOS E IDOSOS: UMA EXPERIÉNCIA DO PROJETO MOVA-BRASIL
}

\author{
FRANCISCA RODRIGUES PINI ${ }^{*}$ \\ ORCID: https://orcid.org/0000-0003-4229-7263
}

RESUMO: A adoção da teoria do conhecimento, formulada pelo educador Paulo Freire, foi o que orientou o Projeto MOVA-Brasil, em seus doze anos de existência (2003-2015). Concebido pelo Instituto Paulo Freire (IPF), pela Federação Única dos Petroleiros (FUP) e pela Petrobras, o Projeto MOVABrasil contribuiu com a transformação social dos territórios nos quais atuou. O processo metodológico do Movimento de Educação de Jovens e Adultos (MOVA) articulou o letramento e a politização ao exercício de cidadania como contribuição à incidência política nos espaços de participação popular. A práxis da Educação Popular em Direitos Humanos permitiu aos diversos segmentos sociais, entre os quais, sistema prisional, comunidades tradicionais, populações indígenas, quilombolas, ciganas, pessoas com deficiência, comunidades de pescadores, ribeirinhos, população do campo e urbana, em conjunto com educadores/as, a construção de processos educativos que dessem visibilidade à baixa oferta de serviços públicos e, ao mesmo tempo, que se inserissem nos espaços públicos, os quais, historicamente, estiveram alijados da participação democrática.

Palavras-chave: Alfabetização. Educação Popular. Direitos Humanos.

\section{ARTICLE - POPULAR EDUCATION ABOUT HUMAN RIGHTS DURING THE LITERACY OF YOUNG, ADULT AND ELDERLY POPULATION: A EXPERIENCE OF PROJETO MOVA-BRASIL}

ABSTRACT: The uptake of the theory of knowledge, formulated by the educator Paulo Freire, was what guided the Projeto MOVA-Brasil during its twelve years of existence (2003-2015). Conceived by the Insitituto Paulo Freire (IPF), the Federação Única dos Petroleiros (FUP) and by the Petrobras, the Projeto MOVA-Brasil contributed for the social transformation of the terrritories where it acted. The methodological process of the Movimento de Educacão de Jovens e Adultos (MOVA) articulated the practice of citizenship literacy

\footnotetext{
'Instituto Paulo Freire, São Paulo, SP, Brasil.

"Assistente Social, Mestre e Doutora em Políticas Sociais PUC/SP, Diretora Pedagógica do Instituto Paulo Freire e Professora Visitante da Universidade Federal de São Paulo (Unifesp), Campus Baixada Santista. E-mail: $<$ fran.pini@paulofreire.org $>$.
} 
and politicization as contribution to the political incidence in the spaces of popular participation. The praxis of Popular Education in Human Rights enabled the multiple social segments, among which are the prison system, traditional comunities, indigenous population, riverside population, people from the countryside and the urban area, combined with the educators, the construction of the educative processes that would give visibility to the low offering of public services and, at the same time, that included themselves in public spaces, which, historically, have been excluded from the democratic participation.

Keywords: Literacy. Popular Education. Human Rights.

\section{INTRODUÇÃO}

O Projeto MOVA-Brasil tem um passado que remonta a 1989. Foi naquele ano que o educador Paulo Freire (1921-1997), quando secretário de Educação do município de São Paulo, no primeiro governo democrático e popular, lançou o Movimento de Alfabetização de Jovens e Adultos da cidade de São Paulo (MOVASP), na Câmara Municipal, em 28 de outubro de 1989.

Ele dava origem, assim, a uma concepção nova de programa de política pública de Educação de Jovens e Adultos, tendo a parceria entre Estado e organizações da sociedade civil como possibilidade de contribuir com a eliminação do analfabetismo, uma vez que, no Brasil, o analfabetismo é estrutural.

A partir desse programa de Educação de Jovens e Adultos, foram concebidos os Fóruns dos Movimentos Populares de Educação de Jovens e Adultos, ${ }^{1}$ os quais foram consolidados, ao longo de quase três décadas, como espaço de debate, reflexão e proposição de políticas sociais na área de educação de jovens e adultos, fortalecendo a participação popular no controle democrático na cidade de São Paulo.

Depois da experiência da gestão na educação pública paulistana, liderada por Paulo Freire, no início dos anos de 1990, várias prefeituras brasileiras, inspiradas no MOVA-SP, criaram seus MOVAs - e muitos educadores e instituições se envolveram na continuidade do movimento.

Diversos municípios brasileiros, como: Diadema, Osasco, Belém, além do estado do Rio Grande do Sul, adotaram a metodologia MOVA como referência para a educação de jovens e adultos, tornando-se este, em algumas gestões públicas municipais e estaduais, em ação estratégica para enfrentar o analfabetismo. 
A Metodologia MOVA resume a trajetória de Freire no campo da alfabetização de adultos, à qual incorporou não só o letramento e a conscientização, mas, igualmente, a necessidade de associar o aprendizado da cultura letrada e do cálculo à cidadania, ao trabalho, à geração de emprego e renda e aos Direitos Humanos (ANTUNES e PADILHA, 2011).

O Instituto Paulo Freire (IPF), a Federação Única dos Petroleiros (FUP) e a Petróleo Brasileiro S.A. (Petrobras), gestores do Projeto MOVA-Brasil, são instituições que têm histórico em ações educativas, de mobilização social e de geração de emprego e renda. Ao conceberem esse projeto, buscaram, por meio de suas instituições, contribuir para a redução do analfabetismo no Brasil, para o fortalecimento da cidadania ativa e a formação profissional das pessoas envolvidas.

O Projeto MOVA-Brasil teve início em 2003, fundamentado na teoria do conhecimento de Paulo Freire. Seus princípios metodológicos, bem como sua estrutura, organização e funcionamento, sua concepção de formação inicial, continuada, avaliação e monitoramento inseremse na tradição da educação libertadora. Ele atua nas causas do analfabetismo ligadas à pobreza.

A conjuntura sociopolítica da época foi favorável à sua realização, tendo em vista a eleição de um governo no campo democrático popular e diversas ações em redes da sociedade civil existentes pelo país.

O programa foi implementado por etapas, conforme tabela abaixo:

\begin{tabular}{|c|c|c|c|c|}
\hline \multicolumn{5}{|c|}{ Quadro dos atendimentos do Projeto MOVA-Brasil nos dez anos } \\
\hline Ano & Turmas & Educandos/as & Municípios & Educadores/as \\
\hline $1^{\text {a }}$ Fase & 543 & 12167 & 161 & 612 \\
\hline $2^{\text {a } \text { Fase }}$ & 525 & 14440 & 128 & 619 \\
\hline $3^{\text {a }}$ Fase & 863 & 23301 & 138 & 994 \\
\hline $4^{\text {a }}$ Fase & 1000 & 24287 & 232 & 1067 \\
\hline $1^{\text {a }}$ Etapa & 1325 & 33979 & 199 & 1472 \\
\hline $2^{\text {a }}$ Etapa & 1329 & 31897 & 194 & 1513 \\
\hline $3^{\text {a } \text { Etapa }}$ & 1311 & 33472 & 184 & 1517 \\
\hline $4^{\text {a } E t a p a ~}$ & 1417 & 41416 & 204 & 1617 \\
\hline 5a Etapa & 1352 & 31612 & 188 & 1545 \\
\hline Total & 9665 & 246571 & 1628 & 10956 \\
\hline
\end{tabular}

Fonte: Sistema MOVA/2014 
O Projeto MOVA-Brasil atuou em 11 estados brasileiros (AL, AM, BA, CE, MG, MA, SE, PE/PB, RJ e RN) e contribuiu com a transformação da realidade de diversas comunidades tais como: quilombolas e indígenas, grupos de pequenos agricultores e produtores rurais, salineiros, pescadores e marisqueiras, ciganos, grupos de artesãos, comunidades de terreiros, grupos de catadores de resíduos sólidos, moradores de favelas e ocupações urbanas, acampados e assentados da reforma agrária, pessoas privadas de liberdades, adolescentes e jovens que cumprem medidas socioeducativas, dentre outros (INSTITUTO PAULO FREIRE, 2014).

As mudanças em relação ao mundo do trabalho em nível mundial exigiram a inter-relação entre educação e trabalho. Nessa perspectiva, em 2012, o Projeto MOVA-Brasil aprimorou as parcerias com os órgãos públicos e privados para assegurar o acesso ao trabalho aos/às educandos/as que ficaram alijados do processo de formação profissional historicamente.

O relatório técnico elaborado pelo Instituto Nacional de Estudos e Pesquisas Educacionais Anísio Teixeira de 2013 (p. 25) afirma que "segundo dados da Pnad/IBGE 2011, o Brasil tem uma população de 56,2 milhões de pessoas com mais de 18 anos que não frequentam a escola e não têm o Ensino Fundamental completo.” E é justamente este total de pessoas que seriam potencialmente educandos da EJA.

A partir do ano de 2000, por meio do parecer do CEB 11/2000 (que versa sobre as Diretrizes Curriculares Nacionais para a Educação de Jovens e Adultos), estabelece-se um marco legal na perspectiva de se reconhecer essa modalidade de forma específica e diferenciada, pois ela apresenta as funções reparadora e equalizadora.

Função reparadora deve ser vista, ao mesmo tempo, como uma oportunidade concreta de presença de jovens e adultos na escola e uma alternativa viável em função das especificidades socioculturais desses segmentos para os quais se espera uma efetiva atuação das políticas sociais. É por isso que a EJA necessita ser pensada como um modelo pedagógico próprio, a fim de criar situações pedagógicas e satisfazer necessidades de aprendizagem de jovens e adultos.

A EJA busca formar e incentivar o leitor de livros e das múltiplas linguagens visuais com as dimensões do trabalho e da cidadania. Ora, isso requer algo mais dessa modalidade, que tem diante de si pessoas maduras e talhadas por experiências mais longas de vida e de trabalho.

Pode-se dizer que estamos diante da função equalizadora da EJA. A equidade é a forma pela qual se distribuem os bens sociais, 
de modo a garantir uma redistribuição e alocação em vista de mais igualdade, consideradas as situações específicas.

Dentre as inúmeras relações que homens e mulheres estabelecem com a sociedade, o trabalho é, sem dúvida, a mais perene. É por meio do trabalho que o ser humano se reconhece como produtor de cultura. $\mathrm{Na}$ experiência realizada por Paulo Freire na década de 1960, em Angicos, a questão do trabalho estava presente nas discussões por meio das imagens criadas pelo artista pernambucano Francisco Brenan para problematizar o conceito de cultura, uma vez que, para Paulo Freire, trabalho e cultura são categorias indissociáveis. Como um ser criador e recriador, o ser humano vai, por meio do trabalho, alterando a realidade e a matéria da natureza, produzindo cultura.

Paulo Freire (1987) concebe o trabalho como uma prática humana de intervenção no mundo e, por isso mesmo, prazerosa, contribuindo para a satisfação pessoal e o bem-estar coletivo. No entanto, o que temos historicamente é a organização do modo de produção capitalista cada vez mais competitiva e as relações de trabalho pautadas pela exploração, exigindo que homens e mulheres produzam cada vez mais, estimulando o consumo para além das necessidades, degradando a vida e o meio ambiente. O trabalho nessa lógica mercantilista apresenta-se como um fardo, castigo e sofrimento.

Frigotto $(1989$, p. 4) afirma que a ideologia cristã e positivista prega a ideia de que todo trabalho dignifica o homem: "Nas relações de trabalho onde o sujeito é o capital e o homem é o objeto a ser consumido, usado, constrói-se uma relação educativa negativa, uma relação de submissão e alienação, isto é, nega-se a possibilidade de um crescimento integral".

Nessa lógica mercantilista, concebem-se expressões que definem homens e mulheres como "capital humano". Contrapondose a essa visão alienante e desumanizadora do trabalho, propomos o trabalho como princípio educativo, entendendo que os trabalhadores têm direito, não só à apropriação da técnica e aos fundamentos científicos do trabalho, mas também à reflexão crítica acerca dos princípios socioambientais necessários à construção de uma sociedade com qualidade social e ambiental.

Foi nesse sentido que, em 2012, a educação profissional como modalidade que permite ao trabalhador ampliar seus saberes profissionais adquiridos ao longo da vida, tornando-o mais qualificado para o exercício de sua profissão, apresenta-se como caminho, mas também como resultado do processo educativo. Qualificá-lo profissionalmente, na perspectiva sociocultural e socioambiental, é 
assegurar ao trabalhador uma formação teórica, técnica e política para lidar com os desafios e demandas que a sociedade atual apresenta, para intervir no contexto social em que vive, transformando as relações de opressão em práticas solidárias, produzindo um desenvolvimento socioambiental efetivo.

No Projeto MOVA-Brasil, a formação profissional e a relação sociocultural e socioambiental foram ancorados em princípios cujas características são:

- O desenvolvimento da consciência crítica, que se constrói por meio de processo formativo que parte da Leitura do Mundo, identifica as situações significativas de cada contexto, problematiza a realidade e busca ações de intervenção.

- A mobilização social e cultural que promove a aproximação entre as pessoas e instituições, articulando com parceiros da região em que se encontram os núcleos do Mova, fortalecendo a economia local.

- O estabelecimento de uma nova lógica do processo produtivo, que valoriza o trabalho comunitário, em lugar do individualismo e da competitividade, e educa para valorizar e viabilizar práticas produtivas sustentáveis.

Segundo Gadotti (2009, p. 29-30), o desenvolvimento sustentável precisa ser ambientalmente correto, socialmente justo, economicamente viável e culturalmente respeitoso das diferenças. Ele supõe, portanto, que existam diversos modos sustentáveis de viver. A fórmula correta seria viver feliz, bem viver, viver plenamente, em harmonia com o meio ambiente, sem destruí-lo.

Por isso, para superar a visão de qualificação, foi preciso incluir tanto habilidades básicas - como conhecimentos essenciais para o exercício da cidadania e do trabalho, comunicação, leitura e escrita, compreensão de textos, segurança no trabalho, direitos humanos quanto habilidades específicas, exigidas para as ocupações a serem trabalhadas, inclusive habilidades de gestão (autogestão).

A economia solidária incorporou, desde seus primórdios, o tema da ecologia e do desenvolvimento sustentável (ANTUNES; NERI; STANGHERLIM, 2011).

Ao longo de 2012 e 2014, o Projeto MOVA-Brasil alcançou cerca de dois mil educandos(as), incidindo na melhoria da qualidade de vida por meio da geração de renda e estabeleceu parcerias para oferta de formação profissional com Sistema S (SENAC, SENAR, SENAI, 
SESI, SEBRAE), SENAES, Institutos de Educação Superior (UERN, IFRN, IFPE), Secretarias Municipais de Educação, Centro de Referência de Assistência Social (CRAS), Centros e Institutos de Educação Tecnológica, ONGs, Secretaria Municipal de Assistência Social, Secretaria Municipal de Saúde, Institutos e Associações (Sistema MOVA,2014).

O contexto social e econômico do Brasil ainda é muito desigual, mesmo com todo investimento realizado nas gestões dos governos democráticos e populares de 2002 até o momento, como nos aponta Moacir Gadotti (2013, p. 35):

As taxas de analfabetismo no Brasil continuam muito altas se comparadas não somente com as dos países desenvolvidos, mas, inclusive, comparadas com as dos países da América Latina. Na primeira década do século 21, o Brasil perdeu 16 posições no Índice de Desenvolvimento da Educação (IDE), indicador da Unesco que mede o desempenho dos países na universalização da educação primária (da $1^{\mathrm{a}}$ a $4^{\mathrm{a}}$ série do Ensino Fundamental a ser completada com 10 anos - distorção série-idade), alfabetização de adultos (taxa acima de 15 anos), paridade e igualdade de gênero e qualidade da educação (medido pelo "índice de sobrevivência" na $5^{a}$ série). Nesse índice, o Brasil, entre 128 países, passou do $72^{\circ}$ para o $88^{\circ}$ lugar, sendo o penúltimo na América do Sul, apenas à frente do Suriname. Em 2005, éramos o $72^{\circ}$; em 2008, o $76^{\circ}$ e em 2010 , o 88 $8^{\circ}$. Nesse indicador, a alfabetização de adultos tem um peso grande, o que puxou o índice para baixo no caso brasileiro.

Esse quadro nos coloca em um contexto de imensa disparidade entre crescimento econômico e crescimento social, e nos convoca a construir propostas com o público envolvido.

Conforme dados do Projeto MOVA-Brasil, em relação ao perfil, as mulheres foram maioria com $60,7 \%$ e os homens com $39,3 \%$, no quesito raça/cor a autodeclaração foi $21,2 \%$ preta, $59,3 \%$ pardo, $17,7 \%$ branco, $0,7 \%$ indígena e $1 \%$ amarelo (INSTITUTO PAULO FREIRE, 2014).

Esse dado revela o deslocamento das mulheres para a vida pública em face das necessidades socioeconômicas. No entanto, exige de nós leituras teóricas e políticas para assegurarmos reflexões que contribuam para o seu processo de autonomia relativa e descoberta para a sua inserção no engajamento social.

Tratando da questão racial, o desafio se amplia na medida em que, historicamente, os processos educacionais não asseguraram espaços nos livros didáticos e tampouco nos ambientes escolares, para tratarmos do regime de escravidão pelo qual o país passou por quase quatro séculos. Por isso, a atualidade de Paulo Freire quando ele afirma: "Aos esfarrapados do mundo e aos que neles se descobrem e, assim, descobrindo-se, com eles sofrem, mas, sobretudo, com eles lutam" (1987, p. 23). 
Em termos quantitativos, a população jovem representou $18,28 \%$ dos atendidos no processo de alfabetização. Em relação aos adultos, a faixa entre 30 e 59 anos constituiu a grande maioria das educandas e dos educandos com 64,38\%. Ainda em 2011, a população idosa no Projeto MOVA-Brasil totalizou 17,34\% (INSTITUTO PAULO FREIRE, 2014).

Os dados relativos aos públicos envolvidos na alfabetização nos desafiaram à formulação de estratégias para integrar as diferentes faixas etárias no processo de socialização da vida cotidiana e buscar, conjuntamente, respostas das políticas sociais: habitação, saúde, assistência social, cultura, esporte, lazer e trabalho, para a inserção aos diversos direitos sociais.

Com a criação da SECADI, ${ }^{2}$ o discurso de governo e as políticas oficiais passaram a reconhecer a alfabetização como uma porta de entrada nos sistemas de ensino. A alfabetização foi integrada à Educação de Jovens e Adultos, com o propósito de garantir continuidade dos estudos. A decisão indica que podemos dar um passo adiante para a superação do "eterno retorno" dos educandos aos cursos de alfabetização.

Para atender à fase inicial da escolarização, o Programa Brasil Alfabetizado (PBA), criado em 2003, repassa recursos de apoio aos estados e municípios parceiros para a alfabetização de pessoas de 15 anos ou mais. De acordo com dados oficiais da SECADI, o PBA atendeu 12.075.428 alfabetizandos durante o período de 2003 a julho 2010, alcançando cerca de 4 mil municípios. Uma breve análise indica que esses números são equivalentes ao montante de pessoas não alfabetizadas, apontadas no último Censo: aproximadamente 14 milhões de pessoas (IBGE 2010).

Em 2012 foi aprovada a Resolução 48/FNDE para ampliar oportunidades de acesso à escola aos jovens, adultos e idosos e o número de matrículas dos educandos que concluem a etapa de alfabetização. Essa resolução regulamentou a transferência automática de recursos financeiros aos estados e municípios para manutenção de novas turmas de EJA que ainda não tivessem sido contempladas pelo Fundeb.

Compreendendo a alfabetização como um caminho de transição para a continuidade dos estudos na EJA, o diálogo estabelecido junto aos poderes públicos locais foi feito na perspectiva de definição de estratégias para garantir o acesso (entrada e permanência dos educandos) à escola. O acompanhamento político-pedagógico realizado pelos/as educadores/as e coordenadores/as locais junto aos/às educandos/as proporciona a identificação e a organização da demanda para viabilizar 
a oferta. Em 2012, 14\% dos educandos atendidos nos 11 estados pelo Projeto MOVA-Brasil foram encaminhados para matrícula na EJA (Relatório MAIS - Lições Aprendidas, 2012).

O Projeto MOVA-Brasil traz, na sua proposta metodológica, a construção de uma relação dialógica e de respeito ao ritmo de aprendizagem e desenvolvimento cognitivo dos educandos. A decisão de continuidade é amadurecida pelos educandos processualmente, ao tempo em que avançam na compreensão da importância da educação ao longo da vida. Sabemos que os educadores atuam no estímulo para a continuidade, mas a motivação dos educandos é que define se eles farão esta transição.

Ao longo do período de alfabetização, é recorrente evidenciar resistências ao ambiente escolar em depoimentos de educandos, quando retratam suas trajetórias de vida e experiências escolares anteriores. Um aspecto relevante que interfere na decisão de continuidade é o acesso à escola. Destacam-se também motivos extraescolares que se relacionam com compromissos profissionais, impedimentos familiares e questões socioeconômicas.

Além dos preconceitos enfrentados pelos sujeitos, a EJA, como modalidade de ensino, tem outros desafios, como: superar a evasão, ${ }^{3}$ promover o investimento em formação continuada dos profissionais, tendo em vista a heterogeneidade das turmas compostas por educandos em níveis cognitivos diferenciados, a elaboração de material didático com linguagem objetiva, o desenvolvimento de uma prática de ensino e aprendizagem - mediatizada pela realidade e experiência - que valorize e reconheça seus conhecimentos prévios, fortaleça neles, educandos, o exercício da cidadania e a sua inclusão social.

Os/as educandos/as do ProjetoMOVA-Brasilexperimentaram essa vivência cotidiana de sujeitos ativos e corresponsáveis pelo seu processo de formação, numa perspectiva emancipatória. Nessa perspectiva, além da prática educativa dialógica, destaca-se a realização dos Encontros de educandos em três instâncias - turmas, núcleos/ municipal e estadual.

No percurso histórico, o Encontro de Educandos/as foi criado no Projeto MOVA-Brasil para oportunizar o encontro entre os/as educandos/as e educadores/as, compartilhar saberes e socializar os avanços e desafios das localidades. No ano de 2012, participaram dos encontros regionais 7.502 educandos/as. Os encontros estaduais contaram com um total de 968 educandos (Relatório MAIS, 2012). 
Esses foram espaços de formação política e de promoção de debates sobre a importância da continuidade dos estudos. A presença de gestores e representantes da EJA permitiu-lhes a escuta das reivindicações das educandas e educandos, bem como o acolhimento de suas proposições referentes à oferta e ao aperfeiçoamento da EJA como política pública.

A relação de parceria do Projeto com fóruns de EJA nos estados gerou também a participação de representantes em formações continuadas dos educadores e coordenadores locais. Por meio desta iniciativa de reflexão coletiva ampliada, houve o reconhecimento da ênfase dada, no processo de ensino e aprendizagem, à valorização dos saberes dos jovens, adultos e idosos, materializada e visualizada por meio da construção do portfólio do/a educando/a.

Além de ser um recurso de avaliação e autoavaliação da intensificação do diálogo junto às equipes de EJA e Secretarias de Educação, o portfólio foi utilizado para validação dos conhecimentos dos educandos e entrada no ensino regular, dispensando, assim, a realização de testes ou provas, e motivando os educandos à continuidade.

As educandas e os educandos traziam para as salas de aula um conjunto de saberes construídos ao longo de suas experiências de vida. Esses conhecimentos devem ser considerados, desenvolvidos e ampliados no trabalho pedagógico, e a eles devem ser acrescentados outros saberes historicamente acumulados e sistematizados pela humanidade.

A tarefa de acrescentar esses conhecimentos, sem anular os saberes dos educandos, é o que podemos definir como ensino. Nessa perspectiva, ensinar exige um exercício constante de ação-reflexãoação. Mais do que isso, exige pesquisa, conforme anuncia Paulo Freire (1997, p. 32):

\footnotetext{
Não há ensino sem pesquisa e pesquisa sem ensino. Enquanto ensino, continuo buscando, re-procurando. Ensino porque busco, porque indaguei, porque indago e me indago. Pesquiso para constatar; constatando, intervenho; intervindo educo e me educo. Pesquiso para conhecer o que ainda não conheço e comunicar ou anunciar a novidade.
}

Para Feitosa (2008, p. 45):

O educador pesquisador, mais do que um transmissor de conhecimento, é aquele que deve acompanhar o processo de construção de conhecimento do educando. Esse acompanhamento pressupõe saber como o educando aprende, quais as hipóteses que constrói, os conflitos cognitivos e os caminhos que encontra para superar esses conflitos. Pressupõe também a observação, o registro e a avaliação desse processo, a fim de possibilitar as intervenções necessárias e provocar situações desafiadoras que ajudem os educandos a questionar suas certezas, para 
que possam considerar a existência de diferentes formas de pensar e, com isso, ampliar seu conhecimento. Essa atuação do educador exige pesquisa e reflexão crítica sobre a prática. Não há lugar para o espontaneísmo.

O Projeto MOVA-Brasil se fortaleceu no diálogo e na interação entre o sujeito que ensina (e aprende ao ensinar) e o sujeito que constrói sua aprendizagem. É nessa relação dinâmica que se deu a construção do conhecimento e da aprendizagem.

\section{PRÁXIS DA EDUCAÇÃO POPULAR EM DIREITOS HUMANOS NO PROJETO MOVA-BRASIL}

A Educação Popular é comprometida com a construção de uma sociedade justa, democrática. Ela parte da realidade da população, disseminada pelos movimentos sociais e valoriza a dialogicidade, a horizontalidade e o conhecimento prévio do sujeito. Promove a autonomia por meio da ação-reflexão-ação. É a expressão do movimento cultural (LIU; PINI; GOES, 2011).

A Educação Popular, sob a formulação freiriana, pode ser entendida como uma concepção de educação para a transformação social, em um contexto de luta contra as diferentes formas de opressão e negação das liberdades. É o exercício da "Educação como Prática de Liberdade", conforme formulação de Paulo Freire. Essa compreensão é fundamental para nos assumirmos como sujeitos críticos e criadores de nossos mundos, da vida cotidiana e dos rumos de nossos destinos e da história (BEISIEGEL, 2008).

A Educação Popular tem um sentido transformador imerso no meio popular. Na concepção histórico-crítica de educação, a concepção de Educação Popular tem um compromisso ético com a mudança da realidade, a qual promove o respeito ao ser humano, combatendo qualquer tipo de discriminação social. (GALVÃO; PADILHA; LEITE, 2011).

A Educação Popular está comprometida com os grupos populares, que são os sujeitos que mais sofrem os múltiplos modos das violências e opressões e ao mesmo tempo luta para a sua inserção em todos espaços educativos da vida social (CEMBALISTA, FEITOSA, 2012).

Nesse processo, há duas categorias centrais. A primeira é a Leitura do Mundo, conceito central da pedagogia freiriana que, ao entender a realidade histórica como uma criação humana, reconhece o ser humano como sujeito capaz de transformar a si próprio e o mundo em que vive. Por meio de uma ação consciente, empreendida 
socialmente, o ser humano pode, em diálogo com seus semelhantes e com a própria realidade, ler o mundo e agir intencionalmente sobre ele, com vistas a sua transformação.

Por meio da Leitura do Mundo emergem os temas geradores que orientam a escolha dos conteúdos a serem problematizados no processo de ensino e aprendizagem, visando a compreensão dessa realidade e a busca de alternativas de intervenção social. Para tal, leva-se em consideração o percurso pedagógico traçado por Freire (1979) de maneira articulada e interdependente: a Leitura do Mundo, a problematização e a intervenção na realidade.

Partir da realidade concreta significa reconhecer que são as necessidades práticas que motivam educadores e educandos a buscar conhecimentos teóricos para compreender a realidade. Voltar à prática para transformá-la requer retomar o exercício de suas ações diárias, com referenciais mais elaborados, e agir de modo mais competente, mais compreensivo e mais comprometido para a transformação social.

A formação dos/as educadores/as, inicial e processual, assegurou os aportes teóricos para conhecer a turma, planejar, avaliar e sistematizar o processo de ensino e aprendizagem.

A Leitura do Mundo inicial, como procedimento metodológico, pautado na dialética e em uma nova razão, é o ponto de partida para a construção do Projeto Eco-Político-Pedagógico do Projeto (PEPP), conhecido na escola como o Projeto Político Pedagógico (PPP). No Projeto MOVA-Brasil é compreendido como o documento que organiza as ações e expressa as concepções teóricometodológica do trabalho pedagógico desenvolvido e articula as questões relacionadas de cada localidade e traduz o sonho coletivo da comunidade da alfabetização para a cidadania planetária, na qual os educandos e educandas atuam como sujeitos do processo de ensino e aprendizagem, com responsabilidades políticas, socioambientais, culturais, locais e globais (INSTITUTO PAULO FREIRE, 2011).

O processo metodológico iniciado com a Leitura do Mundo, por meio da pesquisa sociológica, contribuiu para conhecer o contexto em que vivem os(as) educandos(as), em diferentes aspectos e dimensões: socioambiental, social, política, cultural, socioeconômica e pedagógica.

A dimensão social, por exemplo, compreende desvelar quem é esse sujeito e que lugar ele ocupa no contexto em que vive. Faz parte dessa investigação saber como esse sujeito vê o espaço em que está inserido, quem compõe a comunidade, como ela está organizada, se há equipamentos públicos e quais estão a serviço dos moradores. É necessário captar, também, informações sobre a qualidade no atendimento, se há lazer e atividade comercial, como 
funciona o transporte, se as moradias são adequadas, se há organização comunitária; como se dá a participação e a luta por melhores condições de vida, entre outros.

No segundo momento, conhecido como compartilhamento do mundo lido (Tematização), que ocorre para que a tematização constitua significativo momento na metodologia freiriana, é necessário que o/a educador/a extrapole a prática mecânica da repetição de famílias silábicas e trabalhe com temas de relevância social para os(as) educandos(as).

A tematização é o momento em que as situações detectadas na Leitura do Mundo serão transformadas em temas de estudo. Vários dados foram pesquisados com o estudo da realidade e com a caracterização dos/as educandos/as, mas eles se apresentam desorganizados. Organizar esses dados de maneira a garantir que os problemas detectados sejam incorporados ao processo de alfabetização é tarefa do/a educador/as e da educadora. No entanto, não basta incorporar. É preciso que eles se transformem em temas geradores da ação alfabetizadora. É fundamental que sejam problematizados, que estejam presentes nos debates, nos textos trabalhados, nas situações-problema, nas expressões artísticas, nos cálculos matemáticos, nas produções de textos individuais e coletivos, nos conteúdos de maneira geral.

O tema gerador emerge do conjunto de práticas de investigação. Por sua vez, devem produzir a superação da visão ingênua e promover uma visão mais crítica da realidade. Dada a complexidade do tema, serão gerados também subtemas. O importante é esgotar todas as possibilidades de compreensão do tema e garantir que as áreas do conhecimento contribuam nessa compreensão.

O terceiro momento, denominado reconstrução do mundo lido, trata da problematização, o que significa inserir a dúvida, as diferentes possibilidades de se enxergar um problema. Para se problematizar um fato, o(a) educador (a) deverá lançar mão da pedagogia da pergunta. A pergunta nos leva à "desnaturalização" do natural. Ela nos permite questionar nossas certezas e procurar outras formas de ver o mesmo objeto. A pergunta desestabiliza o óbvio, extrapola o senso comum e é um importante instrumento para a superação da consciência ingênua.

É por meio da problematização da realidade que se imprime ao(à) educando(a) o caráter libertador, pois a ação educativa não é neutra, e é justamente dela que fazemos surgir a realidade escondida.

$\mathrm{Na}$ conjuntura atual, a informação é travestida de conhecimento. Se não for questionada, a informação só informa, mas não conscientiza, não liberta. O/A educador/a pode fazer de suas aulas um campo 
fecundo de conhecimentos e descobertas. Pode fazer da dúvida um caminho para a pesquisa, para a reflexão, para o conhecimento.

Posteriormente, a Leitura do Mundo foi aprofundada, por meio da incursão da turma na comunidade, sendo o conhecimento socializado com a mesma, por meio da Festa Comunitária Cidadã. Esta etapa consistiu na mobilização de todo território, para juntos dialogarem sobre a realidade social, ambiental, cultural, política e econômica que vivenciam cotidianamente, de modo a favorecer o desenvolvimento de práticas sociais que correspondam às necessidades dos/as educandos/as e da comunidade como um todo.

Para a saída a campo, em conjunto com os/as educandos/ as, foi necessária a compreensão sobre as seguintes dimensões: socioeconômica, política, socioambiental, cultural e social, que ocorreu a partir das seguintes reflexões iniciadas em sala de aula:

a) Dimensão Socioeconômica: Principais atividades econômicas locais e/ou regional; principais atividades profissionais desenvolvidas pelos moradores; situação de trabalho e renda etc.

b) Dimensão Cultural: Principais manifestações culturais da localidade; expressões culturais tradicionais tais como: folguedos, música, dança, culinária, língua, lendas, crenças, religião, cinema, teatro, festas de rua, feiras típicas, artesanato e clubes, dentre outras. É importante que nesse item apareçam aspectos da diversidade - a presença de rendeiras, mestres populares, cantadores/as, marisqueiras, pescadores/as etc.

c) Dimensão Social: Qual a situação da saúde pública, segurança pública, moradia, transporte, educação; há políticas públicas voltadas ao atendimento das pessoas com deficiência; funcionamento e qualidade de escolas públicas e privadas; trata-se de comunidade e povos tradicionais - quilombolas, indígenas, ciganos como é percebida a questão da identidade cultural; como é a relação entre eles e o poder público estatal - há políticas públicas de direito à terra, à saúde e à educação etnicamente diferenciada?

d) Dimensão Política: Quais as principais organizações da sociedade civil e dos movimentos sociais que existem em âmbito local - sindicatos, associações, organizações não governamentais; há lideranças comunitárias, lideranças religiosas, lideranças políticas; como é a composição e atuação da Câmara de Vereadores; como é a participação dos moradores nos espaços de decisão política, tais como: Orçamento Participativo, Conselhos Municipais, reuniões com representantes da Prefeitura; existem audiências públicas; há organizações partidárias; quem são os parceiros do Projeto MOVABrasil, entre outras ações? 
e) Dimensão Socioambiental: A comunidade é atendida com sistema de tratamento de água e esgoto e saneamento básico; há situações de desmatamento e reflorestamento; existem tratamento do lixo, áreas de preservação de manguezais, mananciais - rios, lagos, represas e lençóis freáticos, florestas, entre outros?

Os diferentes momentos de Leitura do Mundo precisam articular-se à dimensão cognitiva. Interessa-nos diagnosticar e saber como potencializar a aprendizagem do(a) educando(a), partindo do que ele já sabe, já construiu e incorporou e aquilo que ainda precisa ser construído. Nesse âmbito, podem ser destacadas três categorias desta dimensão que compõem o perfil dos educandos: socialização, participação e leitura/escrita/oralidade.

A segunda categoria fundamental da teoria do conhecimento de Paulo Freire é o Círculo de Cultura, compreendido como o processo de ensino e aprendizagem em que o educando ocupa o papel de investigador e traz para o centro do debate os elementos da realidade para identificar as palavras geradoras. A relação entre educador e educando é de compartilhamento de saberes diferentes, cada um com uma bagagem de conhecimento e sua parcela de responsabilidade na construção de novos conhecimentos. Paulo Freire faz menção ao Círculo de Cultura, como:

[...] os Círculos de Cultura são precisamente isto: centros em que o Povo discute os seus problemas, mas também em que se organizam e planificam ações concretas, de interesse coletivo. [...] estabelece-se um dinamismo entre os Círculos de Cultura e a prática transformadora da realidade, de tal modo que passam a ativar-se e reativar-se mutuamente. (FREIRE, 1976, p. 141-142).

Cabe ao educador lançar mão de procedimentos metodológicos para que os educandos reconheçam que sabem um conjunto de coisas e ajam para saber o que ainda não sabem. Esses saberes devem ser sempre contextualizados, a fim de que os/as educandos/as percebam a importância desses conhecimentos para suas vidas e lutem pelo bem viver coletivo (BRANDÃO, 1985).

Hoje, ao nos depararmos com o desafio de reinventar Paulo Freire, não podemos desconsiderar que somos, assim como os educandos e educandas com os quais trabalhamos, produtores de cultura e transformamos o mundo com o nosso trabalho - e, por meio dele, nos transformamos também. Essa é a dimensão antropológica da cultura refletida pelo educador Paulo Freire. Essas categorias encontram sustentação na concepção de Educação Popular como práxis política, a qual está diretamente vinculada aos saberes da comunidade e dos/as educandos/as. 
O reconhecimento e a valorização desses saberes são constitutivos da Educação Popular e da educação como prática da liberdade, tendo em vista estabelecer a devida articulação entre esses conhecimentos e os saberes historicamente sistematizados pela humanidade, na perspectiva da qualidade social que buscamos com a prática pedagógica, que tem como principal finalidade contribuir para a construção da autonomia de todos os envolvidos. Como afirma Brandão (apud PADILHA; FAVARÃO; MORRIS; MARINE, 2011, p. 63),

Na concepção libertadora de educação, o educando não pode ser visto como
uma caixa vazia que recebe os depósitos dos educadores. O educador Paulo
Freire denominou essa concepção de bancária, pela semelhança que há entre ela
e um banco. Na concepção bancária, a relação que se estabelece entre educador
e educando é de sujeito e objeto, sendo o educando um mero recipiente pronto
a receber os saberes do educador. Nesse caso, não há diálogo e a relação entre os
participantes é vertical, ficando marcada a hierarquia entre educador e educando.

Essa concepção de educação defendida por Freire perpassa a compreensão da incompletude e inacabamento do ser humano. Desse modo, todo tempo é tempo de aprender, pois não é um ato finito, mas de constante renovação. Essa perspectiva dialoga com a noção de alfabetização assumida na Declaração de Jomtien (1990), associada a uma visão ampla de educação, que se estende ao longo de toda vida e que considera, portanto, que as pessoas estão permanentemente se educando em diversos âmbitos sociais, para além da escola.

No percurso metodológico, a avaliação ocupa um lugar estratégico, na medida em que ela possibilita rever o caminho traçado no planejamento para o alcance dos objetivos. Os dados oficiais da EJA indicam um índice elevado de evasão escolar pelo fato de não haver acompanhamento processual das ações. No Projeto MOVA-Brasil, a avaliação e o monitoramento processual aconteceram em três momentos:

1. Avaliação inicial. Ocorreu por meio, dos elementos da realidade do(a) educando(a) e da comunidade a partir do que foi identificado na Leitura do Mundo. O desejo de uma avaliação dialógica não é identificar o que falta para o(a) educando(a), mas sim o que o(a) educando(a) conhece e sabe, pois, assim, o planejamento será orientado a partir desse olhar.

As atividades foram elaboradas de acordo com as especificidades de cada localidade/comunidade.

Para o diagnóstico inicial, foram elaboradas atividades de escrita, leitura, oralidade e matemática em folhas soltas, pois estas compuseram parte do portfólio de cada educando(a). 
2. Avaliação processual. As atividades que ocorreram durante o processo tiveram como objetivo identificar quais aprendizagens e conhecimentos os jovens, adultos e idosos construíram ao longo do processo educativo e quais ainda precisavam ser consolidadas. O registro e sistematização dessa análise reorientou o planejamento pedagógico, a fim de garantir a construção das aprendizagens no processo de alfabetização dos(as) educandos(as).

3. Avaliação final. Ao final do Projeto, o/a educador/a apresentava o percurso de aprendizagem de cada um dos/as educandos/ as para sugerir e dialogar sobre os possíveis encaminhamentos. Assim, $\mathrm{o} / \mathrm{a}$ educador/a retomava a sistematização das avaliações iniciais, as atividades de meio de processo, o portfólio e, por fim, a avaliação final que possibilitava identificar o que os(as) educandos(as) aprenderam, levando em conta todo o processo desenvolvido (SANTOS; NASCIMENTO, 2011).

O Portfólio é um instrumento fundamental no trabalho pedagógico do/a alfabetizador(a), pois é um instrumento que mantém atualizados os registros de todo o processo de aprendizagem dos alfabetizandos(as). Segundo Madalena Freire (2001), o registro:

Permite também a retomada e revisão de encaminhamentos feitos, porque possibilita a avaliação sobre a prática, constituindo-se fonte de investigação e replanejamento para a adequação de ações futuras. O registro permite a sistematização de um estudo feito ou de uma situação de aprendizagem vivida. $\mathrm{O}$ registro é História, memória individual e coletiva eternizadas na palavra grafada. É o meio capaz de tornar o educador consciente de sua prática de ensino, tanto quanto do compromisso político que a reveste (p.10).

Para compor o portfólio, foi consensuado com os/ as educadores/as, que ele seria constituído por duas atividades significativas de leitura ou escrita e duas atividades de matemática, realizadas em cada mês, de cada educando/a, que demonstrassem o avanço e/ou a dificuldade apresentada em seu processo de ensino e aprendizagem. Esse instrumento pedagógico permitiu observar o desenvolvimento das aprendizagens de cada um durante o processo (NASCIMENTO; SILVA, 2011).

Em cada atividade foi sugerida a inclusão no planejamento do/a educador/a os aspectos importantes da realização da atividade como: falas relevantes do educando/a durante a realização da atividade; a dificuldade ou avanço apresentada pelo educando/a; o tempo que o educando/a levou para concluir a atividade (se este for um aspecto significativo). 
O horizonte do/a educador/a e dos/as educandos/as do Projeto MOVA-Brasil é trilhar um caminho de continuidade dos estudos rumo à escola pública e construir uma educação anticapitalista (MÉSZÁROS, 2005).

A Declaração Universal dos Direitos Humanos, a Constituição Federal de 1988 e aLDB (Lei de Diretrizes e Bases da Educação Nacional $\mathrm{n}^{\circ}$ 9394/96) apontam a educação como um direito de todos e dever do Estado. Assegurar a oferta da escolarização é responsabilidade do poder público que deve viabilizar e estimular o acesso e a permanência do educando à escola, considerando suas características, seus interesses, condições de vida e de trabalho (ARROYO, 2005).

A EJA é uma modalidade de ensino que atende estudantes jovens, adultos e idosos maiores de 15 anos de idade que não concluíram o Ensino Fundamental, em todos os níveis da educação básica. Contudo, as recorrentes e pontuais campanhas de alfabetização e a histórica inconsistência de políticas efetivas de continuidade dos estudos desmobilizam o interesse dos/as educandos/as e descontinuam a oferta e o acesso da educação como uma questão de direito.

Aprofundar a compreensão da realidade em que estão inseridos, serem capazes de ler e escrever a partir de seus contextos e de suas narrativas de vida, visando ao exercício da cidadania e à escrita de uma nova história do Brasil, com justiça, democracia e sustentabilidade é o significado social e político de um projeto como esse, para o Brasil.

\section{CONSIDERAC̣ÕES FINAIS}

Podemos dizer que a Educação Popular é uma Educação para os Direitos Humanos, uma vez que promove a mobilização social para lutar por direitos e construção de valores de respeito e de alteridade (LIU; PINI; GOES, 2011, p. 34).

Em continuidade ao legado freiriano, comprometido com a emancipação humana e a transformação social, nós nos colocamos diante da necessidade de lutar e construir um mundo com justiça social para todos e todas. Nesse sentido, o reconhecimento da diversidade está atrelado à luta pelo direito à diferença como ponto de partida, vislumbrando a igualdade material como ponto de chegada. Assim se traduz a urgência em lutarmos pela equidade, entendida como direito à igualdade de oportunidades, considerando as diferenças (PINI; MORAES, 2011). 
Por isso, afirmamos a Educação Popular em Direitos Humanos como concepção de educação imersa na realidade e com as populações que sofrem as maiores violações de seus direitos.

A tão propagada "igualdade na diversidade" só pode ser proferida se a igualdade for entendida como sinônimo de igualdade material e a diversidade como a diferença que faz de cada ser humano um ser único, origem da noção de dignidade humana: a humanidade que diferencia cada um(a), tornando-o/a diferente dos/as demais e igual em direitos.

Como expoente de uma educação emancipadora, democrática e cidadã, não discriminatória, antirracista, comprometida com a liberdade religiosa, com respeito às diferenças e à sustentabilidade socioambiental, a experiência do Projeto MOVA-Brasil estabeleceu como diretriz metodológica de sua ação alfabetizadora a Educação em Direitos Humanos, por lutar com as populações marginalizadas econômica e socialmente pela garantia de direitos, e impulsionar o exercício da cidadania na perspectiva de uma educação que tem como finalidade a emancipação dos sujeitos, para a transformação social.

A experiência do Projeto MOVA-Brasil comprovou que política pública se faz com planejamento, intencionalidade políticopedagógica e com investimento público.

O Projeto MOVA-Brasil contribuiu com o desenvolvimento comunitário na perspectiva da economia solidária, do fortalecimento da agricultura familiar, do artesanato, do desenvolvimento sustentável, da articulação de redes sociais e interfaces com os temas da juventude, das culturas populares e tradicionais. As questões de gênero, a valorização das identidades de povos indígenas, populações negras, quilombolas, ciganos, movimentos sociais, dentre outros sujeitos políticos que, organizados, conseguiram encaminhar suas lutas seculares em torno de seus direitos e da transformação da realidade vivida.

Ao longo dos 12 anos de atuação do Projeto, importantes centros urbanos do país foram alcançados, como Recife, Rio de Janeiro, Salvador, Belo Horizonte, Fortaleza, Manaus, Maceió etc., pequenas comunidades situadas no campo (assentamentos e acampamentos de reforma agrária, comunidades quilombolas e indígenas, grupos de pescadores e marisqueiras, pequenos agricultores, artesãos etc.).

O Projeto MOVA-Brasil contribuiu com inúmeras experiências de levantamento de situações-problema nas comunidades atendidas por meio da metodologia da Leitura do Mundo e, posteriormente, o encaminhamento dessas questões a partir da reivindicação de melhorias, envolvendo as áreas da saúde, educação, moradia, segurança, mobilidade urbana, direito das pessoas privadas de liberdade, meio ambiente e sustentabilidade, direito à terra, dentre outras. 
Em diversas localidades os/as educandos/as se envolveram com a participação social e se engajaram nos fóruns de EJA, contribuindo com a luta da educação.

O trabalho sobre gênero foi condição essencial para compreendêlo no contexto das relações sociais e assegurar a visibilidade da questão da mulher no cotidiano das turmas de jovens, adultos e idosos, respeitando as necessidades e especificidades numa perspectiva emancipatória.

Ao atender mais de 250 mil mulheres e homens em seus 12 anos de existência, o Projeto MOVA-Brasil não apenas ensinou a ler e escrever, mas proporcionou o aumento da autoestima dos sujeitos, possibilitando a inclusão de mulheres e homens no mundo do trabalho, da cultura e em outros âmbitos sociais, melhorando a qualidade de vida, estimulando a solidariedade e a colaboração entre os gêneros (CISNE, 2018).

Outro impacto importante foi a abordagem da questão etnicorracial. O racismo no Brasil continua provocando opressões e explorações. Assegurar a reflexão sobre as violações possibilitou educandos/as e educadores/as construírem estratégias de enfrentamento (MOURA, 1994).

O Projeto MOVA-Brasil promoveu formação sobre a história da África e dos africanos na formação inicial e continuada. Essa reflexão se insere no projeto eco-político-pedagógico e fez parte da implementação da Lei no 10.639/2003, que alterou a Lei de Diretrizes e Bases da Educação Nacional e tornou obrigatório o ensino de história e cultura afro-brasileiras nos estabelecimentos de ensinos fundamental e médio, oficiais e particulares. Conforme os dados do Sistema MOVAM, 79,2\% das pessoas atendidas são negras e pardas.

Podemos afirmar que o processo metodológico, alinhado à concepção da teoria do conhecimento do educador Paulo Freire, contribuiu com os resultados exitosos no processo e ao final da alfabetização, tendo aproximadamente $50 \%$ dos/as educandos/as sido encaminhados para a continuidade dos estudos.

Os subsídios pedagógicos elaborados pelo Instituto Paulo Freire para educandos/as e educadores/as também se apresentaram como um diferencial, pois possibilitaram a pesquisa, o ensino contextualizado e a construção de novos conhecimentos e sistematizações.

O Projeto MOVA-Brasil contribuiu com ações para atender as metas 9 e 10 do Plano Nacional de Educação (PNE), aprovado em 2014. A meta 9 prevê: elevar a taxa de alfabetização da população com 15 (quinze) anos ou mais para 93,5\% (noventa e três inteiros e cinco décimos por cento) até 2015 e, até o final da vigência deste PNE, 
erradicar o analfabetismo absoluto e reduzir em 50\% (cinquenta por cento) a taxa de analfabetismo funcional, e a meta 10: oferecer, no mínimo, 25\% (vinte e cinco por cento) das matrículas de educação de jovens e adultos, nos ensinos fundamental e médio, na forma integrada à educação profissional (Relatório MAIS, 2014).

No que se refere à meta 9 , há uma atuação direta quando as turmas de alfabetização são instaladas nas localidades onde é maior o índice de analfabetismo, como a região Nordeste. Esse trabalho conjunto entre Instituto Paulo Freire, Federação Única dos Petroleiros (FUP) e Petrobras demonstrou como a sociedade civil, o movimento sindical e a empresa de capital misto podem contribuir com a redução da pobreza.

Outra ação concreta é a meta 10. A fim de atingi-la, o Projeto MOVA-Brasil atuou de forma articulada e integrada com as secretarias municipais e estaduais de educação, para assegurar o encaminhamento dos/as educandos/as para a continuidade dos estudos.

Reconhecer e realizar a educação em Direitos Humanos como um dos eixos fundamentais do direito à educação exige posicionamentos claros quanto à promoção de uma cultura de direitos. Essa concepção de Educação em Direitos Humanos é refletida na própria noção de educação expressa na Constituição Federal de 1988 e na Lei de Diretrizes e Bases da Educação Nacional (Lei n 9.394/1996).

\section{REFERÊNCIAS}

ANTUNES, Ângela; PADILHA, Paulo Roberto. Metodologia MOVA. São Paulo: Instituto Paulo Freire, 2011. (Caderno MOVA-Brasil, v. 2).

; NERI, Juliana Fonseca de Oliveira; STANGHERLIM, Roberta. Economia

Solidária. São Paulo: Instituto Paulo Freire, 2011. (Caderno MOVA-Brasil, v. 4).

ARROYO, MIGUEL. Educação de jovens - adultos: um campo de direitos e de responsabilidade pública. In: SOARES, Leôncio; GIOVANETTI, Maria Amélia; GOMES, Nilma (org.). Diálogos na Educação de Jovens e Adultos. Belo Horizonte/MG: Autêntica, 2005.

BEISIEGEL, Celso de Rui. Política e Educação Popular: a teoria e a prática de Paulo Freire no Brasil. Brasília: Líber, 2008.

BRANDÃO, Carlos Rodrigues. A educação como cultura. São Paulo: Brasiliense, 1985.

BRASIL. Constituição da República Federativa do Brasil: promulgada em 5 de outubro de 1988.

Estatuto do idoso: Lei Federal n. ${ }^{\circ}$ 10.741, de 01 de outubro de 2003. Brasília, DF:

Secretaria Especial dos Direitos Humanos, 2004.

LDB - Lei de Diretrizes e Bases da Educacional. Lei 9394/96. 
MEC; ACÃO EDUCATIVA. Educação de Jovens e Adultos: Proposta Curricular para o $1^{\circ}$ Segmento do Ensino Fundamental. São Paulo; Ação Educativa; Brasília, DF: MEC, 2001.

CEMBALISTA, Sílvia; FEITOSA, Sonia Couto Souza. Conviver, respeitar e valorizar a diversidade. São Paulo: Instituto Paulo Freire, 2012.

CISNE. Mirla: SANTOS. Silvana Mara. Feminismo, diversidade sexual, e Serviço Social. São Paulo: Cortez, 2018.

INSTITUTO NACIONAL DE ESTUDOS E PESQUISAS EDUCACIONAIS ANÍSIO TEIXEIRA. Relatório Censo Escolar da Educação Básica, 2013. Disponível em: <http://download.inep.gov.br/educacao_basica/censo_escolar/resumos_tecnicos/ resumo_tecnico_censo_educacao_basica_2013.pdf>. Acesso em: 10 fev. 2019.

FEITOSA, Sonia Couto Souza. Método Paulo Freire: a reinvenção de um legado. Brasília: Liber Livros, 2008.

FREIRE, Paulo. Ação cultural para a liberdade. Rio de Janeiro: Paz e Terra, 1976.

Educação e mudança. Rio de Janeiro: Paz e Terra, 1979.

Pedagogia da autonomia: saberes necessários à prática educativa. São Paulo: Paz e Terra, 1997.

Pedagogia da indignação. São Paulo: Editora Unesp, 2000.

Pedagogia do oprimido. 17. ed. Rio de Janeiro: Paz e Terra, 1987.

FREIRE. Madalena. O papel do registro na formação do educador. In: Diálogos Textuais. São Paulo: Espaço Pedagógico. 2001.

FRIGOTTO, Gaudêncio. É falsa a concepção de que o trabalho dignifica o homem. Comunicado: Revista da Universidade da Amazônia, Belém, 7 ago. 1989.

GADOTTI, Moacir. Economia solidária como práxis pedagógica. São Paulo: Instituto Paulo Freire, 2009.

(org.). MOVA-Brasil 10 anos: Movimento de Alfabetização de Jovens e Adultos. São Paulo: Instituto Paulo Freire, 2013.

GALVÃO, Mariana; PADILHA, Paulo Roberto; LEITE, Rosângela. Diversidade e Direitos. São Paulo: Instituto Paulo Freire, 2011. (Caderno MOVA-Brasil, v. 5).

INSTITUTO PAULO FREIRE. RELATÓRIO MAIS. Lições Aprendidas, São Paulo, 2012. . Sistema MOVA Brasil, 2011. São Paulo - SP. . Sistema MOVA Brasil, 2012. São Paulo - SP. Sistema MOVA Brasil, 2014. São Paulo - SP.

LIU, Emiliano Palmada; PINI, Francisca Rodrigues de Oliveira; GÓES, Washington. Educação Popular. São Paulo: Instituto Paulo Freire, 2011. (Caderno MOVA-Brasil, v. 3).

MEC. Parâmetros em Ação- Alfabetização, Texto 22. Brasília, 1999.

MÉSZÁROS, István. A educação para além do capital. São Paulo: Boitempo, 2005. 
MOURA. Clóvis. O racismo como arma ideológica de dominação. Edição 34, São Paulo: Revista Princípios1994.

NASCIMENTO, Luiz Marine José do; SILVA, Rodrigo Costa da (Org.). Alfabetização inicial de jovens, adultos e idosos: a ousadia de fazer e o dever de mostrar. São Paulo: Editora e Livraria Instituto Paulo Freire, 2011.

PADILHA, Paulo; FAVARÃO, Maria; MORRIS, Erick; MARINE, Luiz (Org.). Educação para a cidadania planetária: Currículo Intertransdisciplinar em Osasco. São Paulo: Editora e Livraria Instituto Paulo Freire, 2011.

PINI, Francisca Rodrigues de Oliveira; MORAES, Célio Vanderlei (org.). Educação, participação política e direitos humanos. São Paulo: Editora e Livraria Instituto Paulo Freire, 2011.

SECRETARIA-GERAL DA PRESIDÊNCIA DA REPÚBLICA. Secretaria Nacional de Articulação Social e Departamento de Educação Popular e Mobilização Cidadã. Marco de Referência da Educação Popular para as políticas públicas, Brasília, 2014.

SANTOS, Alessandra Rodrigues de; NASCIMENTO, Luiz Marine do. Educação de Adultos. São Paulo: Instituto Paulo Freire, 2011. (Caderno MOVA-Brasil, v. 1).

UNESCO. Conferência Mundial sobre Educação para Todos. Declaração mundial sobre educação para todos. Plano de ação para satisfazer as necessidades básicas de Aprendizagem. Jomtien, 1990.

\section{NOTAS}

${ }^{1}$ GADOTTI, Moacir (Orgs.). MOVA-Brasil 10 anos: Movimento de Alfabetização de Jovens e Adultos. São Paulo: Instituto Paulo Freire,2013, p.27.

${ }^{2}$ SECADI - Secretaria de Educação Continuada, Alfabetização e Diversidade e Inclusão criada em 2004. A partir de 2011, com a reestruturação (Decreto n ${ }^{\circ}$ 7.480, de 16 de maio de 2011) do MEC, a Secretaria de Educação Continuada, Alfabetização e Diversidade (SECAD) - passou a ser denominada Secretaria de Educação Continuada, Alfabetização, Diversidade e Inclusão (SECADI).

${ }^{3}$ Conceito que precisa ser problematizado na EJA, pois esta condição se apresenta de formas variadas e com justificativas nesta modalidade. Muitos educandos ficam em mobilidade, por exemplo.

Submetido: $24 / 09 / 2018$

Aprovado: 22/02/2019

Contato:

Rua Santos Egídio, n 551, apto 101 - Santa Terezinha

São Paulo $\mid$ SP | Brasil

CEP 02.461-011 